\title{
Knowledge, Attitude, Behavior, and Practice toward Minimal Intervention Dentistry among Dental Professionals in Bengaluru City, India
}

\author{
${ }^{1} \mathrm{G}$ Suma, ${ }^{2}$ Yasin Salman
}

\begin{abstract}
Aims: The emphasis on caries prevention and early detection has led to a paradigm shift toward the concept of minimal intervention dentistry (MID). Despite the benefits of MID in the preservation of dental components and significant reliability, the clinical application is still limited. This study was, therefore, aimed to assess the knowledge, attitude, practices, and clinical decision behaviors of dental professionals of Bengaluru city, Karnataka, India.
\end{abstract}

Materials and methods: A cross-sectional questionnairebased survey was conducted in Bengaluru city, Karnataka, India, in the year 2016 for a period of 1 month among dental professionals. Data were collected using 25 questions focused on knowledge, attitude, practice, and behavior toward MID. The descriptive data were analyzed; statistical evaluation was done by chi-square test.

Results: Among 100 respondents, the mean scores for knowledge, attitude, and clinical decision were $3.57 \pm 0.685,0$ to 4 ; $18.84 \pm 2.21,5$ to 25 ; and $4.69 \pm 0.78,0$ to 6 respectively. Data showed that dental professionals had adequate knowledge and a positive attitude toward MID. A weak positive correlation was seen between knowledge and attitude $(r=-0.059$, $p=0.55)$ and knowledge and clinical decision $(r=-0.050$, $p=0.62)$.

Conclusion: Adequate knowledge and positive attitude neither influenced their clinical decision-making behavior nor their practical application of MID. A nationwide awareness campaign has to be done to alarm the authorities in making and implementing a course of action for updating the practice and clinical decisions behaviors of dental professionals in the country.

Keywords: Dental caries, Dental education, Dental professionals, Minimal intervention dentistry.

How to cite this article: Suma G, Salman Y. Knowledge, Attitude, Behavior, and Practice toward Minimal Intervention Dentistry among Dental Professionals in Bengaluru City, India. J Health Sci Res 2017;8(1):20-24.

Source of support: Nil

Conflict of interest: None

\footnotetext{
${ }^{1}$ Reader, ${ }^{2}$ Postgraduate Student

1,2Department of Pediatric and Preventive Dentistry, VS Dental College \& Hospital, Bengaluru, Karnataka, India

Corresponding Author: G Suma, Reader, Department of Pediatric and Preventive Dentistry, VS Dental College \& Hospital, Bengaluru, Karnataka, India, Phone: +91-9880964010 e-mail: sumadoc@yahoo.co.in
}

\section{INTRODUCTION}

A current inclination toward evidence-based dental practice has led to a new revolution in technologies involving remineralization, adhesive restorative materials, and complete comprehension of cariology. Thus, caries prevention and early detection have emerged to become an integral part of dental practice. ${ }^{1}$

The emphasis on caries prevention and early detection has led to paradigm shift toward the concept of minimal intervention dentistry (MID). Martin et al have employed the term "minimal intervention," "minimally invasive," or "preservative dentistry," which was earlier named as "prophylactic odontomy." The MID can be defined as "A philosophy of professional care concerned with first occurrence, earliest possible cure of disease on micro (molecular) levels, followed by minimally invasive and patient friendly treatment to repair irreversible damage caused by such disease." ${ }^{2}$ The first breakthrough in the field of minimally invasive treatment in dentistry was seen in the early 1970s, with the application of diamine silver fluoride followed by preventive resin restoration (PRR) in 1978 and the atraumatic restorative treatment in 1980s approach and the chemomechanical caries removal concepts in the 1990s. ${ }^{2}$

The MID includes the following principles: Early caries diagnosis and assessment of caries activity, the classification of caries depth and progression using radiographs, the assessment of individual caries risk (high, moderate, low), the arresting of active lesions, the remineralization and monitoring of noncavitated lesions, the placement of restorations in teeth with cavitated lesions using minimal cavity designs, and assessing disease management outcomes at preestablished intervals. Disease eradication and regular follow-up form the cornerstone of MID. ${ }^{3}$ According to several authors, despite the benefits of minimally invasive procedures in the preservation of dental components and significant reliability with proposed guidelines by public health policies, the clinical application is still limited in public health programs. The available clinical knowledge and scientific evidence allow paramount changes to be introduced in the management of dental caries. ${ }^{4}$

This study was, therefore, aimed to assess the knowledge, attitude, practices, and clinical decision behaviors 
of dental professionals of Bengaluru city, Karnataka, India. Secondly, it was observed whether the knowledge they acquired translates to positive attitudes, practices, and clinical decision behaviors toward practicing MID.

\section{MATERIALS AND METHODS}

The present study was a cross-sectional questionnairebased survey conducted in Bengaluru city, Karnataka, India. About 100 dental professionals were randomly selected. Dentists who were not willing to participate in the study and who were unavailable during visit to their clinics/hospitals were excluded from the study. A pretested, structured, and validated questionnaire was adapted from questionnaires used previously in a study done by Gaurav Gupta et al. ${ }^{5}$

Questionnaires were distributed to the dentists, and the filled questionnaires were collected. The duration of the study was 1 month (August 2016). Only completely filled forms were considered for analysis.

The questionnaire consisted of four sections with four questions on knowledge, five questions on attitude, ten questions on the practice, and six questions on clinical decision behavior. All the questions were close ended. The questions on knowledge were based on multiple choice patterns. The questions on attitude and practice were based on Likert scale with questions on attitude ranging from strongly disagree (1) to strongly agree (5) and those on practice ranged from never (1) to always (5). One question on initial caries in the section pertaining to attitude was reverse scored so that a higher score meant a more positive attitude. The clinical decision behavior was assessed using international caries detection and assessment system (ICDAS) codes 1 to 6 with the description of the lesion. The choices of treatments included fluoride application, PRRs, sealants, and treatment options based on GV Black classification. For the codes 1 and 2, fluoride and/or pit and fissure sealants were considered as the correct options. Sealants and PRRs were considered as the correct option for ICDAS code 3. For codes 4 to 6, option of treatments based on surgical or conventional GV Black principle was considered as the correct option. ${ }^{6}$

Data were entered in a Microsoft Excel spreadsheet and descriptive data were analyzed, chi-square test and independent t-test were used to compare the mean scores. The correlation between the variables value $\leq 0.05$ is considered as statistically significant. For test, a $p<0.05$ is considered as statistically significant.

\section{RESULTS}

A total of 100 questionnaires that were completely filled were analyzed. Knowledge, attitude, practice, and clinical decision behavior scores were calculated separately. Most of the dental professionals correctly selected the responses to each question on knowledge. However, the response to the question on PRR elicited wrong responses from $20 \%$ of the dental professionals (Table 1). The attitude of the dental professionals toward MID was positive with more than $70 \%$ in agreement with the benefits of application of MID procedures and concepts. However, $29 \%$ of the dental professionals exercised the option of "agree" and "strongly

Table 1: Distribution of dental professionals according to their knowledge of MID

\begin{tabular}{|c|c|c|c|c|}
\hline Questions & Correct $N(\%)$ & Incorrect N (\%) & Chi square & $p$-value \\
\hline $\begin{array}{l}\text { 1. Atraumatic restorative treatment is done with the help of: } \\
\text { (a) Hand instruments } \\
\text { (b) Micro motor } \\
\text { (c) Air rotor } \\
\text { (d) Air abrasion }\end{array}$ & 99 (99) & $1(1)$ & 96.040 & $0.00^{*}$ \\
\hline $\begin{array}{l}\text { 2. Material used for pit and fissure sealants are: } \\
\text { (a) Unfilled resin } \\
\text { (b) Zinc polycarboxylate cement } \\
\text { (c) Amalgam } \\
\text { (d) Silicate cements }\end{array}$ & $82(82)$ & $18(18)$ & 40.960 & $0.00^{*}$ \\
\hline $\begin{array}{l}\text { 3. Preventive resin restoration is based on principles of: } \\
\text { (a) Extension } \\
\text { (b) Prevention of the extension } \\
\text { (c) Extension for prevention } \\
\text { (d) None of the above }\end{array}$ & $80(80)$ & $20(20)$ & 36.000 & $0.00^{*}$ \\
\hline $\begin{array}{l}\text { 4. Which of the following is not used for remineralization of teeth? } \\
\text { (a) Chlorhexidine } \\
\text { (b) Strontium fluoride } \\
\text { (c) Sodium fluoride } \\
\text { (d) APF gel }\end{array}$ & $96(96)$ & $4(4)$ & 84.640 & $0.00^{*}$ \\
\hline
\end{tabular}

*Statistically significant 
agree" to use GV Black's principle of "extension for prevention" for initial caries (Table 2). The results for each of the 10 subquestions of practice behaviors related to MID performed are presented in Table 3. The subquestions regarding practice behavior had the greatest percentage of dental professionals selecting "always or most of the time" for the use of topical fluoride (96\%) and prescribing chlorhexidine for caries control (40\%). The majority of dental professionals chose incorrect options for ICDAS codes 2 to 4 , i.e., caries process in the outer and inner halves of the enamel that required remineralization, sealants or PRRs. However, majority chose correct options for ICDAS codes 1 and 6 that are on minimal or extensive lesions requiring invasive treatments (Table 4).

Table 2: Distribution of dental professionals according to their attitude toward MID

\begin{tabular}{|c|c|c|c|c|c|c|c|}
\hline Questions & $\begin{array}{l}\text { Strongly } \\
\text { disagree } N(\%)\end{array}$ & $\begin{array}{l}\text { Disagree } \\
N(\%)\end{array}$ & $\begin{array}{l}\text { Uncertain } \\
N(\%)\end{array}$ & $\begin{array}{l}\text { Agree } \\
N(\%)\end{array}$ & $\begin{array}{l}\text { Strongly } \\
\text { agree N (\%) }\end{array}$ & $\begin{array}{l}\text { Chi } \\
\text { square }\end{array}$ & $p$-value \\
\hline $\begin{array}{l}\text { 1. Do you think fluoride application is an } \\
\text { effective way of preventing dental caries? }\end{array}$ & 0 & $2(2)$ & $2(2)$ & $57(57)$ & 39 (39) & 91.120 & $0.00^{*}$ \\
\hline $\begin{array}{l}\text { 2. Do you think G. V. Black's "extension for } \\
\text { prevention" is relevant for initial caries? }\end{array}$ & $20(20)$ & $40(40)$ & $11(11)$ & $23(23)$ & $6(6)$ & 34.300 & $0.00^{*}$ \\
\hline $\begin{array}{l}\text { 3. Do you think adhesive restorative materials } \\
\text { have helped in preserving tooth structure? }\end{array}$ & $0(0)$ & $4(4)$ & $18(18)$ & $54(54)$ & $24(24)$ & 53.280 & $0.00^{*}$ \\
\hline $\begin{array}{l}\text { 4. Do you think caries risk assessment should } \\
\text { be carried out for all patients? }\end{array}$ & $2(2)$ & $6(6)$ & $10(10)$ & $59(59)$ & $23(23)$ & 107.500 & $0.00^{*}$ \\
\hline $\begin{array}{l}\text { 5. Do you think application of pit and fissure } \\
\text { sealants is for the larger benefit to society? }\end{array}$ & $1(1)$ & $1(1)$ & $17(17)$ & $56(56)$ & $25(25)$ & 102.600 & $0.00^{*}$ \\
\hline
\end{tabular}

*Statistically significant

Table 3: Distribution of dental professionals according to practice of MID

\begin{tabular}{|c|c|c|c|c|c|c|c|}
\hline Procedures & $\begin{array}{l}\text { Never } \\
N(\%)\end{array}$ & $\begin{array}{l}\text { Rarely } \\
N(\%)\end{array}$ & $\begin{array}{l}\text { Sometimes } \\
N(\%)\end{array}$ & $\begin{array}{l}\text { Often } \\
N(\%)\end{array}$ & $\begin{array}{l}\text { Always/ } \\
\text { most of the } \\
\text { time } N(\%)\end{array}$ & $\begin{array}{l}\text { Chi } \\
\text { square }\end{array}$ & $p$-value \\
\hline $\begin{array}{l}\text { 1. Caries risk assessment (diet, oral hygiene, salivary test, } \\
\text { etc.) }\end{array}$ & $11(11)$ & $18(18)$ & $28(28)$ & $30(30)$ & $13(13)$ & 14.900 & $0.00^{*}$ \\
\hline 2. Remineralize with CPP/amorphous calcium phosphate & $9(9)$ & $14(14)$ & $45(45)$ & $27(27)$ & $5(5)$ & 52.800 & $0.00^{*}$ \\
\hline 3. Remineralize with topical fluoride application & $0(0)$ & $10(10)$ & $32(32)$ & $47(47)$ & $11(11)$ & 38.160 & $0.00^{*}$ \\
\hline 4. Prescribe chlorhexidine for caries control & $32(32)$ & $15(15)$ & $13(13)$ & $26(26)$ & $14(14)$ & 14.500 & $0.00^{*}$ \\
\hline $\begin{array}{l}\text { 5. Seal adjacent pits and fissures of amalgam restorations } \\
\text { with a sealant }\end{array}$ & $23(23)$ & $18(18)$ & $28(28)$ & $23(23)$ & $8(8)$ & 11.500 & $0.02^{*}$ \\
\hline $\begin{array}{l}\text { 6. Seal adjacent pits and fissures of composite } \\
\text { restorations with a sealant }\end{array}$ & $15(15)$ & $7(7)$ & $30(30)$ & $39(39)$ & $9(9)$ & 38.800 & $0.00^{*}$ \\
\hline 7. Repair defective restorations instead of replacement & $19(19)$ & $23(23)$ & $35(35)$ & $15(15)$ & $8(8)$ & 20.200 & $0.00^{*}$ \\
\hline 8. Slot and tunnel preparations & $16(16)$ & $25(25)$ & $22(22)$ & $33(33)$ & $4(4)$ & 23.500 & $0.00^{*}$ \\
\hline 9. Preventive resin restoration & $0(0)$ & $13(13)$ & $39(39)$ & $35(35)$ & $13(13)$ & 23.360 & $0.00^{*}$ \\
\hline 10. Atraumatic restorative treatment & $3(3)$ & $14(14)$ & 39 (39) & $35(35)$ & $9(9)$ & 51.600 & $0.00^{*}$ \\
\hline
\end{tabular}

*Statistically significant

Table 4: Distribution of dental professionals according to their clinical decision behavior toward MID

\begin{tabular}{|c|c|c|c|c|c|}
\hline $\begin{array}{l}\text { ICDAS } \\
\text { codes }\end{array}$ & Clinical conditions & $\begin{array}{l}\text { Correct } \\
N(\%)\end{array}$ & $\begin{array}{l}\text { Incorrect } \\
N(\%)\end{array}$ & $\begin{array}{l}\text { Chi } \\
\text { square }\end{array}$ & $p$-value \\
\hline 1. & $\begin{array}{l}\text { Opacity with air-drying: White/brown is not consistent with the clinical appearance } \\
\text { of sound enamel and is limited to the confines of the pit and fissure area }\end{array}$ & $99(99)$ & $1(1)$ & 96.040 & $0.00^{*}$ \\
\hline 2. & $\begin{array}{l}\text { Opacity without air-drying: White, brown, which is wider than the natural fissure/ } \\
\text { fossa, i.e., not consistent with the clinical appearance of sound enamel }\end{array}$ & $48(48)$ & $52(52)$ & 0.160 & 0.68 \\
\hline 3. & $\begin{array}{l}\text { Surface integrity loss: The base and walls of the cavity within enamel and dentin } \\
\text { are not visible }\end{array}$ & $79(79)$ & $21(21)$ & 33.640 & $0.00^{*}$ \\
\hline 4. & $\begin{array}{l}\text { Underlying gray shadow: This lesion appears as a shadow of discolored dentin } \\
\text { visible through an apparently intact enamel surface, which may or may not show } \\
\text { signs of localized breakdown }\end{array}$ & $48(48)$ & $52(52)$ & 0.160 & 0.68 \\
\hline 5. & Distinct cavity: There is frank cavitations, and dentin is exposed & $100(100)$ & $0(0)$ & 81.000 & $0.00^{*}$ \\
\hline 6. & $\begin{array}{l}\text { Extensive cavity: Obvious loss of tooth structure and dentin is clearly visible on the } \\
\text { walls and at the base in a cavity that involves at least half of the tooth surface }\end{array}$ & $95(95)$ & $5(5)$ & 83.800 & $0.00^{*}$ \\
\hline
\end{tabular}

*Statistically significant 
The mean scores for knowledge, attitude, and clinical decision were $3.57 \pm 0.685$, range 0 to $4 ; 18.84 \pm 2.21$, range 5 to 25 ; and $4.69 \pm 0.78$, range 0 to 6 respectively.

A weak positive correlation was seen between knowledge and attitude $(\mathrm{r}=-0.059, \mathrm{p}=0.55)$, which means that as there was an increase in the knowledge score, there was a more positive attitude seen among the participants.

A weak positive correlation between knowledge and clinical decision $(r=-0.050, p=0.62)$ was seen, which means that as there was an increase in the knowledge score, there was an increase in the clinical decision scores of the participants.

\section{DISCUSSION}

Minimal intervention dentistry is the most modern approach for the management of dental caries. This shift from intervention to prevention is still in the course of being integrated in a systematic and comprehensive manner in the dental ${ }^{7}$ practice.

In this study, dental professionals had adequate knowledge regarding MID procedures with a mean score of $3.57 \pm 0.685$. The results were similar to the study of Brazilian dental professionals where majority had adequate knowledge about MID procedures. ${ }^{4}$ However, it was observed that more than half $(51.5 \%)$ of the respondents either had no knowledge or only possessed a little knowledge about MID in a study done in Riyadh and AlKharj. ${ }^{3}$

An overall positive attitude $(18.84 \pm 2.21)$ toward MID was observed in this study; positive attitude toward the application of pit and fissure sealant $(79 \%)$ is in agreement with another Indian study $(86 \%){ }^{8,9}$ The attitude of dental practitioners in this study toward caries risk assessment was $43 \%$ similar to another Indian study of $49.66 \%$, where it was reported that they would use caries activity test in the future, and half of the samples agreed to such an assessment in Riyadh and AlKharj. ${ }^{4,9}$ About $96 \%$ of the dental professionals agreed that fluoride application was an effective way of preventing caries similar to the responses in the other Indian study and also among Iranian senior dental students. ${ }^{9,10}$ A substantive percentage $(29 \%)$ of the dental practitioners in this study were of the opinion that the GV Black principles could be applied for initial caries. Dental students in Florida were willing to supervise and curb enamel lesions in their practices, while one-third of senior Iranian students preferred to place restorations in enamel lesions on proximal and occlusal surfaces respectively. ${ }^{11,12}$

As time passes, it is generally seen that there is gradual decline in knowledge of preventive dental care among dentists. ${ }^{13}$ Among the MID procedures, the remineralization of teeth with topical fluoride application and prescribing chlorhexidine for caries control were either "always" or "most often" answered by 58 and
$40 \%$ in this study respectively. Similarly, in the study of US dental surgeons, topical fluoride was most often practiced, while microbial testing and casein phosphopeptides and amorphous calcium phosphate (CPP/ACP) application were the least practiced among all other MID procedures. ${ }^{1}$ However, in this study, remineralization with $\mathrm{CPP} / \mathrm{ACP}$ and repair defective restorations instead of replacement were the least performed among MID procedures. Sushanth et $\mathrm{al}^{13}$ in 2015 reported that dentists are generally aware of remineralization options for demineralized teeth like CPP (49.5\% aware) and tooth mousse ( $95.9 \%$ aware). In the present study, only $9.4 \%$ of the dental professionals "always" practiced MID procedures; in contrast, $49.4 \%$ of Brazilian dentists practiced MID procedures. ${ }^{4,5}$

A major section of the dental professionals chose incorrect treatment options for preventive treatment (codes 2-4) than for the treatment with minimal decay or more extensive decay requiring surgical approach. A majority of Australian dental students chose correct modality, i.e., remineralizing for the lesions confined to enamel, whereas similar to this study, more than $50 \%$ of the Brazilian and $77 \%$ Iranian dentist chose to intervene and restore a caries lesion confined to enamel. ${ }^{5}$

The dentist must acknowledge and be updated with the ever-changing and improving scientific knowledge in the field of dentistry. Professional organizations and governmental agencies should take up stronger initiatives to inform patients and dental professionals about the benefits and merits of MID. One of the demerits of the present study is that it was restricted only to one city; the authors recommend that such studies be carried out on a nationwide basis to alert the authorities in drafting and implementing a course of action to help update the practice and clinical decision behavior of dental professionals in the country.

\section{CONCLUSION}

This study was an important step in providing information on dental professional's perceptions with regard to MID, and to offer insight into future directions to be taken in this area. The adequate knowledge and positive attitude neither influenced their clinical decision making behavior nor their practical application of MID. Greater effort should be made by the concerned authorities to enlighten the patients and dental professionals regarding the benefits and merits of MID.

\section{REFERENCES}

1. Gaskin EB, Levy S, Guzman-Armstrong S, Dawson D, Chalmers J. Knowledge, attitudes, and behaviors of federal service and civilian dentists concerning minimal intervention dentistry. Mil Med 2010;175(2):115-121. 
2. Gujjar KR, Sumra N. Minimally invasive dentistry - a review. Int J Clin Prevent Dent 2013 Jun;9(2):109-120.

3. Shah AH, Sheddi FM, Alharqan MS, Khawja SG, Vohra F, Akram Z, Faden AA, Khalil HS. Knowledge and attitude among general dental practitioners towards minimally invasive dentistry in Riyadh and AlKharj. J Clin Diagn Res 2016 Jul;10(7):ZC90-ZC94.

4. Katz CR, de Andrade Mdo R, Lira SS, Ramos Vieira EL, Heimer MV. The concepts of minimally invasive dentistry and its impact on clinical practice: a survey with a group of Brazilian professionals. Int Dent J 2013 Apr;63(2):85-90.

5. Gupta G, Shanbhag N, Puranik MP. Perceptions regarding minimal intervention dentistry among dental interns in India: a cross-sectional survey. Int J Contemp Dent Med Rev 2015. Article ID 330115.

6. Doméjean S, Gaucher C. Minimal intervention in cariology identification stage detection and classification of caries lesions. J Minim Intervent Dent 2011;4:38-41.

7. Ehsan S, Rafique A, Ehsan A, Tahir S. Minimal intervention dentistry: conceptual integration in the dental curriculum in cariology. Pak Oral Dent J 2015 Mar;35(1):120-124.
8. Premnath $\mathrm{P}$, John J. Knowledge, attitude and practice toward preventive dental care among dental professionals in Chennai. J Educ Ethics Dent 2015 Jan-Jun;5(1):20.

9. Agrawal R, Saxena V, Singh N, Dutta SD, Bhushan P. Dental students' knowledge and attitude towards caries management and prevention. J Res Adv Dent 2014;3:82-89.

10. Khami MR, Virtanen JI, Jafarian M, Murtomaa H. Preventionoriented Practice of Iranian senior dental students. Eur J Dent Educ 2007 Feb;11(1):48-53.

11. Autio-Gold JT, Tomar SL. Dental students' opinions and knowledge about caries management and prevention. J Dent Educ 2008 Jan;72(1):26-32.

12. Afsaneh P, Fatemeh SS, Javad KM. Knowledge, attitude and self reported practice of senior dental students in relation to caries risk assessment. Oral Health Dent Manage 2014;13:1106-1111.

13. Sushanth VH, Kalra1 DD, Kumar NPG, Prashant GM, Bhate P, Imranulla M. Assessment of knowledge, attitude, and practice regarding preventive options in oral care among dentists in Davangere city, Karnataka: a cross-sectional study. Dent Med Res 2015 Jan-Jun;3(1):20. 